\title{
The role of educational reward in the process of learning
}

Mircea Cătălin Dîrţu, Bogdan Neculau \& Camelia Soponaru 


\title{
The role of educational reward in the process of learning
}

\author{
Mircea Cătălin Dîrţu ${ }^{\mathrm{a}^{*}}$, Bogdan Neculau ${ }^{\mathrm{a}}$ \& Camelia Soponaru ${ }^{\mathrm{a}}$ \\ ${ }^{a}$ Faculty of Psychology and Educational Sciences, Alexandru Ioan Cuza University of Iași, 3 Toma Cozma Street, Iași, 700554, Romania
}

*Corresponding author: camelia.soponaru@uaic.ro

Abstract

Keywords:

Reward; Learning

theories; Education;

Educational psychology
Unfortunately, since the first theory of scientifically grounded learning has emerged and up to present theories, there are two minuses that directly affect the status of the reward. A first drawback is that psychologists and researchers in the related fields have not yet reached an agreement regarding the role of reward in the process of learning. If some of them praise it up to the skies while others put a blame on it, one can only ascertain that the role of reward is so complex that it is not thoroughly understood, yet.

The second matter is related to the first and it seems to be more serious. It refers to improper communication, deficient to the educational specialists and, why not, to the general public, of the major discoveries made by the researchers regarding the importance of reward for the proper course of the learning process. That is why, the aim of this article is not only to present the stage the researches on reward and their interpretation are in, but also to particularly present them in a form that is more accessible to all those involved in the educational process, in expectation that the information comprised herein will be useful and easier to apply.
Zusammenfasung

Schlüsselworte: Belohnung; Theorien lernen; Bildung; Wissenschaftliche Kommunikation.
Leider gibt es seit dem Aufkommen der ersten Theorie des wissenschaftlichen fundierten Lernens und bis zu den heutigen Theorien zwei Minuspunkte, die sich direkt auf den Status der Belohnung auswirken. Ein erster Nachteil ist, dass Psychologen und Forscher in verwandten Bereichen noch keine Einigung über die Rolle der Belohnung im Lernprozess erzielt haben. Wenn einige es in Ruhm erheben, während andere es beschuldigen, können wir nur sehen, dass die Rolle der Belohnung so komplex ist, dass sie immer noch unzureichend verstanden wird.

Das zweite Problem verbindet sich mit dem ersten Problem und scheint ernster zu sein. Es bezieht sich auf die unzulängliche Kommunikation, die den Bildungsfachleuten und, warum auch nicht, der Öffentlichkeit fehlt, über die wichtigen Entdeckungen, die die Forscher hinsichtlich der Bedeutung der Belohnung für den reibungslosen Ablauf des Lernprozesses gemacht haben. Deshalb möchten wir in diesem Artikel nicht nur den Stand und die Interpretation der Belohnungsforschung darstellen, sondern auch sie in einer Form präsentieren, die für die Bildungsprozess-Beteiligten zugänglicher ist, in der Hoffnung, dass Ihnen die enthaltenen und vorhandenen Informationen nützlich und leichter sein werden und dass sie leicht anwendbar werden.

\section{Reward in the light of past and present educational research}

More than a century has passed since the first major theory of learning was developed, a theory which has dominated the field of education for almost fifty years and it has been a source of inspiration for the subsequent theories. There is an explanation why Thorndike's theory, for this is the topic under discussion, was so influential and always actual. The discovery of the decisive role of reward in learning was exactly what brought celebrity to this theory. For centuries, those responsible for the education of children were guided by the "Repetitio est mater studiorum" principle, but it proved to be a false one and, by this, unsuccessful. More precisely, Thorndike has experimentally demonstrated that repetition does not create new learning, but only reinforces what has already been learnt, the true "mater studiorum" has confirmed to be the reward, the one and only effect of our creative learning behaviour, of connections, as Thorndike used to name the results of the learning process (Thorndike, 1898).

The repetitive drill principle was not the only one to be targeted and eliminated. Another major victim of Thorndike's research was the sanction or, as one commonly refers to, the punishment. Also considered an infallible pedagogical principle, the "Spare the rod and spoil the child" principle was mostly applied throughout in time, and it has now proved to be false. Only that, unlike the former, which, if reformulated, can become useful after the process of learning has taken place, the latter is completely prejudiced. Punishment, as Thorndike has concluded, doesn't create anything. That is, it doesn't leave room for learning and, which is equally important, it neither destroys nor eliminates the skills that have 
already been learnt, either good or bad. The only thing that sanction can determine is to lead to a reformulation of behaviours so that in the future, punishment will no longer be applied (Thorndike, 1910). A representative example of the misuse of punishment as a pedagogical principle and implicitly of its failure is the "correction schools" coercive institution where it was proven that the convicted minors did not give up their antisocial behaviours under the threat of punishment, but, on the contrary, they even perfected them in the hope of avoiding future punishments. In other words, these schools proved to be, in fact, genuine criminal and crime academies.

To conclude, the lesson taught by Thorndike is plain and clear. If you force the children to repeat meaninglessly and/ or punish them, the learning efficiency will decrease to zero. But no matter how simple this conclusion is and no matter how well it is scientifically based, one notices that even nowadays some of those involved in the educational phenomenon have not given up on those principles that have been demonstrated to be false.

The acknowledgment of the importance of reward in learning reached its peak in the mid-twentieth century, at the same time with Skinner's theory being formulated, a theory so influential that its creator was designated as the most important psychologist of all times by the Americans. Although apparently this theory seems to contradict Thorndike's classical connectionism, proposing a reversed connectionism, what actually occurs in Skinner's theory only enhances the role of learning. In reality, Skinner's experiments show that reward is not an effect or a luxury product of behaviour, but it is actually the stimulus itself. And what fascinated the Americans' pragmatic nature was Skinner's promise that any behaviour of an individual can be shaped in the direction desired by society if the reward-stimulus is applied on time (that is, immediately) and in its optimal form, (Skinner, 1966). What is also interesting here is the fact that for this psychologist too, repetition hasn't got any creative value in the process of learning, and the negative role of punishment is even better emphasized, its main effect being considered to be the behaviour of avoidance of the source that produces sanction.

Turned into a goddess, it would have been impossible for the reward to be able to receive greater honours than those given to Thorndike's classical theory and to Skinner's famous theory. That is why, obviously, there were disputes regarding the overvalued role of reward, at first reserved, even within the behaviourist trend dominated by patriarch Skinner. Thus, the Brelands (1961), initially Skinner's disciples, discovered that the power of reward to generate learning is not absolute. Working in Hollywood in the field of animal training with the specific purpose of making them learn complex behaviours, the two researchers found out that the limits of the species to which the animal belongs to will not allow the learning of some behaviours that go beyond those limits. The animal does not learn everything, but only what it is able to, which is granted by limits of heredity.

Guthrie, a radical behaviourist himself $(1934,1959)$, went even beyond and dethroned the reward by taking away its status as creator of learning. According to his theory everybody memorises all the moves produced, and this memorization takes place spontaneously and immediately. But Skinner's disciples' protests were not too vehement, because Guthrie's experiments highlighted the spontaneity and naturalness we learn with, and the reward was nevertheless given the major role of decision on which multiple competing skills will be kept and which ones will be abandoned. Reward was further on granted the dominant position in learning, even though, this time, it carried out only in a managerial and not in a creative role.

Skinner's followers did not react in same manner when Garcia's research (1955) led to the conclusion, unacceptable for them, that learning can occur over a quite long period of time since the reward's or punishment's action. The idea that reward must appear as soon as possible after behaviour has occurred so as learning to take place successfully was inspired by Pavlov's research and was confirmed by Skinner's experiments, so that it became a basic postulate in the latter's theory, too. That's why countless accusations of imposture and dishonesty began to be made against Garcia, even reaching to racist attacks stemming from the fact that Garcia, the psychologist, was of Mexican origin. Those passionate attacks on Garcia's conclusions appeased in time as more and more psychologists replicated his experiments and reported the same results and conclusions. The revolutionary conclusion that everybody can learn the behaviours that are rewarded much later will be taken over and developed into the cognitive theories, as it will be seen later on.

If behaviourist theories evolved with reward as a central pillar, the new cognitivist trend shaped after World 
War II shifted its attention from reward to the meaningful role of shaping up and mediator of processes that facilitate learning. As long as classical behaviourism did not accept the existence of any intermediary process between stimulation and behaviour, learning was conceived as an extremely simple process where it is sufficient for the reward to meet action or behaviour, for learning to occur. Cognitivists were the ones who complicated the process of learning by highlighting the role of mediating processes that intervene between reward and behaviour.

The first successful attempt to introduce new elements into the over-simplified process of learning, as it was seen up to then, belonged to Tolman (1948). Although strongly influenced by the gestalt movement that rejected behaviourist ideas, Tolman was keen on maintaining and interpreting the results emerging from his own research performed under the umbrella of behaviourism. That is why he called his theory "intentional behaviourism", "molar behaviourism" or "sign-gestalt behaviourism". His highly ingenious and praiseworthy experiments have also shown that the path from motivation to reward is guided by many other factors.

According to his theory, hopes (or expectations as they are called today) are such factors. Searching for rewards is never done blindly, but only according to a list of priorities or preferences. In reality, a chimpanzee which expects to get a banana, but which receives a salad leaf instead, although it is hungry and usually eats salad, will look for the banana, refusing to eat its favourite least expected food.

Another factor that comes between as a mediator in learning is the pursuit of a purpose, the existence of an intention. In its basic form, this intermediary factor is highlighted by the fact that the animal learns much more easily where it finds its food and, by comparison, with a greater difficulty, the movements that have to be made in order to reach it. The existence of any purpose or intention has been vehemently denied by the classical behaviourism. It is Tolman's merit of scientifically proving their existence with the help of such experiments.

Furthermore, Tolman's highly ingenious experiments also highlighted the fact that the animal never displays singular, disordered or unintegrated behaviours, but it has got a coherent representation of the environment in which it moves, creating a clear pattern of the movements that it will make. Nowadays, the concept of an inner schema is one of the most important in the cognitive psychology.
Despite his different interpretation given to it, the fact that Tolman also emphasized the existence and importance of spontaneous, non-compensated learning, as Guthrie did, is interesting.

Another interesting experiment brought into discussion the limits of reward from a different perspective. A group of chimpanzees which used to solve puzzles just for fun, spontaneously and with great pleasure, began to receive grapes as a reward whenever they successfully completed a puzzle. The spontaneity with which the chimpanzees were playing disappeared very quickly and they stopped playing unless they received their reward. The result of this experiment shows clearly enough that overcompensation is by no means a positive action. It could be said that overcompensation still produces learning but, at the same time, a clear alteration in the quality of learning can be also noticed. The lesson to be taught here is that over-rewarding, as any other exaggeration, loses its initial qualities (Laland, 2018).

More than that, the effect investigated and theorized by Premack (1962) reconsiders the role of sanction in learning, too. This effect refers to the fact that people are willing to accept a small and reasonable sanction in exchange for a more consistent future reward. This is exactly what grandparents or mothers everywhere apply when they promise their children dessert if they make an effort to eat what they consider good, but they refuse. Sanction, in a homeopathic quantity, proves here to play an important role in certain special learning situations, (Terhune \& Premack, 1974).

One of the best-known theories of learning belonging to the second half of the twentieth century, Bandura's (1971) socio-cognitive theory, must be brought to attention, too; it is about the famous "bobo-doll" experiment in which it is shown that the tendency of children is to copy the adults' deeds, because they assume that these deeds will bring them some benefits. An easy way to learn, as Bandura's research shows, comes from people's willingness to examine and interact with others. People are social beings and that is why they cannot escape from the influence that others exert on them, the process of learning often occurring on social grounds.

At the same time with the cognitive psychologists, humanistic psychologists have also tried to remove learning from the punishment-reward duality. People have emotions and feelings, and those involved in the 
complex process of learning cannot escape from these experiences. The human being cannot be defined only as a behavioural being as termed by behaviourism, nor just as an intelligent being as cognitivism lets us think. Perhaps the theory of attachment best highlighted this aspect, starting with Bowlby and influenced by psychoanalysis at its beginning, a theory which nowadays is confirmed both by ethology and the evolutionist psychology.

There is not a more eloquent example for the involvement of emotions in the process of learning than the joy of kindergarten children when they receive incentives such as the red round sticker dots when displaying desirable behaviours, expected by educators. At a first glance, the children's behaviour is far from any logical thought. A red round sticker dot has no material value, cannot be eaten, and not even kept for a longer time as it is the case of later diplomas and cups. Apparently, children's exaggerated joy is a free, silly one. In fact, those red round sticker dots have a profound significance and support the thesis of the attachment theory. They "inform" the children, when offered, that the educator deeply appreciates them and that this appreciation can guarantee that they will be protected in the future as well. Hugs, caresses, praises or kind words are all rewarding emotional stimuli that enhance learning. Thus, the children's need to feel emotionally secure can determine them to learn behaviours that bring balance and safety, in a very easy manner.

Many forms and types of influence that reward can take or have when it is involved in shaping people's behaviour, that is in learning, have been reviewed so far. And, for sure, it is still a long way until the comprehension of all the subtle or less subtle ways in which learning determines people's evolution. And, if Aristotle advised everyone to establish the value of a certain thing by imagining what would happen if it did not exist, one can easily infer that removing the reward from the process of learning and replacing it with sanction would create monsters of stagnation or slowing of human's evolution, abandonment, avoidance, disappointment, frustration, etc. There are enough reasons to make any effort possible to better and profoundly understand the subtle game of reward in the process of learning.

\section{Authors note:}

The authors have equal contributions to this article.

Mircea Cătălin Dîrţu is Lecturer at Faculty of Psychology and Educational Sciences from "Alexandru Ioan Cuza" University of Iaşi. His Ph.D. is in Psychology and he teaches Personality Psychology, Introduction in Psychology and Psychology History courses. He published numerous studies in different speciality journals focusing on Common Sense Psychology, Personality Psychology and Educational Psychology.

Bogdan Neculau is Ph.D. Lecturer at the Teachers' Training Department of the Psychology and Education Sciences, "Alexandru Ioan Cuza" University of Iasi. He graduated at the same university, both The Faculty of Theology and the Faculty of Psychology and Education Sciences and he obtained a Ph.D. in Education Sciences (2007). He teaches courses on Introduction in Pedagogy, Curriculum Theory and Methodology, Teaching Theory and Methodology, Evaluation Theory and Methodology, Communication Pedagogy, Educational Management to the students who would like to pursue a career in teaching. He has published a series of articles and studies in the area of General Didactics, Christian Pedagogy and Teacher Training. He is a reviewer of scientific committee of numerous conferences and scientific events that have been organized within the university and pre-university environment.

Camelia Soponaru is Associate Professor at Faculty of Psychology and Educational Sciences from "Alexandru Ioan Cuza", University of Iaşi. She has a Ph.D. in Psychology since 2008 with a thesis on Social Clinical Psychology. She teaches Vocational and Career Counselling and Cognitive Behavioural Therapy for bachelor and master's students form Psychology academic specialization. She published books and numerous studies in speciality journals in Clinical Psychology, Psychotherapy and Educational Psychology areas.

\section{References}

Bandura, A. (1971). A social learning theory. Morristown, NJ: General Learning Corporation.

Breland, K., Breland, M. (1961). The misbehavior of organisms. American Psychologist, 16, 681-684.

Garcia, J., Kimeldorf, D.J., \& Koelling R.A. (1955). Conditioned aversion to saccharin resulting from exposure to gamma radiation. Science, 122, 157-158.

Guthrie, E.R. (1934). Reward and Punishment. Psychological Review, 41, 450-460. 
Guthrie, E.R. (1959). Association by contiguity. In S. Koch (ed.). Psychology: a study of a science (pp. 158-198). New York, NY: McGraw-Hill Book Company.

Laland, K.N. (2018). Darwin's Unfinished Symphony: How Culture Made the Human Mind. Princeton, NJ: Princeton University Press.

Premack, D. (1962). Reversibility of the reinforcement relation. Science, 136, 255-257.

Skinner, B.F. (1966). Contingencies of Reinforcement. New York, NY: Appleton-Century-Crofts.
Terhune, J. \& Premack, D. (1974). Comparison of reinforcement and punishment functions produced by same contingent event in the same subjects. Learning and Motivation, 5, 221-250.

Thorndike, E.L. (1898). Some experiments on animal intelligence. Science, 7, 818-826.

Thorndike, E.L. (1910). The contribution of psychology to education. Journal of Educational Psychology, I, 5-12.

Tolman, E.C. (1948). Cognitive maps in rats and men. The Psychological Review, 55(4), 189-208. 